\title{
Associations Between Telomere Length and Insulin Resistance in American Adults $\ A$ Cross-Sectional Study from the US National Health and Nutrition Examination Survey, 1999-2002
}

\section{Rongpeng Gong}

Qinghai Medical College: Qinghai University Medical College https://orcid.org/0000-0003-1117-0956

Zheng Li

Qinghai Provincial People's Hospital

Ya Liu

Qinghai University Medical College

Gang Luo

Qinghai University Medical College

Lixin Yang

Qinghai Provincial People's Hospital

Xiaoxing Wei ( $\nabla$ weixiaoxing@qhu.edu.cn )

Qinghai University Medical College

Original investigation

Keywords: insulin resistance, telomere, cardiovascular, diabetes, gene, NHANES

Posted Date: January 29th, 2021

DOI: https://doi.org/10.21203/rs.3.rs-154493/v1

License: (a) (1) This work is licensed under a Creative Commons Attribution 4.0 International License.

Read Full License 


\section{Abstract}

\section{Background}

Some previous studies seemed to confirm a link between telomere length and many chronic diseases, but in recent years, a growing body of evidence has shown a weak link between telomere length and some chronic diseases. In previous studies insulin resistance has been listed as a sign of arterial aging, diabetes, and especially atherosclerosis. However, there is insufficient evidence that telomere length is associated with insulin resistance in US adults. Therefore, we tried to find evidence of telomere length and insulin resistance based on the NHANES1999-2002 database.

\section{Methods}

We used multiple logistic regression analysis to test the relationship between telomere length and insulin resistance, and drew a smooth fitting curve between telomere length and insulin resistance without adjustment. At the same time, groups of people were divided according to age, gender, race, etc., and multivariate Logistic analysis was conducted after adjusting covariables to test the association between telomere length and insulin resistance in different groups.

Results

In this study, after the adjustment of covariables. Telomere length was not associated with insulin resistance in U.S. adults and was not statistically significant.

Conclusions

Since there is a significant association between insulin resistance and race, further investigation and study is needed to determine whether telomere length is related to the risk of insulin resistance in other populations. At the same time, more research is needed to explore the link between telomeres and chronic disease in the future.

\section{Background}

Currently, we believe that mammalian aging is characterized by two key features: one is age-dependent relaxation of the nutrient senses. The second is age-dependent telomere length wear (1). The risk of insulin resistance increases with age and this is the most common form of unregulated nutrient perception in the general population $(2,3)$.

If both insulin resistance and telomere wear reflect the aging process to some extent, then whether there is a link between human telomere dynamics, i.e., telomere length $(T L)$ and age-related wear, and insulin resistance?

Many studies have explored the correlation between leukocyte telomere length and insulin resistance index or type 2 diabetes. Most of these studies $(4-11)$ but not all $(12,13)$ found a negative correlation between 
leukocyte telomere length and insulin resistance. Or that white blood cell telomere length was shorter in type 2 diabetes than in people without type 2 diabetes.

However, this finding is currently being challenged by increasing evidence that telomere length is determined early in life (14), and another study has shown that the rate of telomere shortening in adult white blood cells is definite (15). Therefore, genetic factors (16) and intrauterine environment (17-19) may play a role in the formation of leukocyte telomere length.

Although a number of studies seem to show an association between leukocyte telomere length and insulin resistance. However, in the current study, evidence of an association between insulin resistance and leukocyte telomere length in American adults remains weak. Our aim was to investigate whether the occurrence of insulin resistance is related to leukocyte telomere length using the U.S. National Health and Nutrition Examination Survey (NHANES) database.

\section{Methods}

\section{data sources}

NHANES, an ongoing cross-sectional study conducted by the National Center for Health Statistics (NCHS), is a national database containing information about the health and nutritional status of adults and children in the United States. NHANES has been collecting data since 1999, including unique information on interviews and medical examinations. State department of health and human services (HHS) official website (http://www.cdc.gov/nchs/nhanes/nannes_quemplairees.htm) provides data are analyzed and illustrated. The NHANES protocol was approved by the NCHS Research Ethics Review Board, and informed consent was obtained from all participants. The NHANES database consists of five main components, including demographic data, dietary data, examination data, laboratory data, and questionnaire data. More detailed information about NHANES is available on the official website.

\section{Participant selection}

We conducted a series of data analyses based on data from two consecutive NHANES survey cycles: 1999-2000 and 2001-2002. After screening for a variety of conditions, we finally selected 21,004 (19992000:9,965 cases;2001-2002:11,039 cases) and 2,427 participants were selected for the final data analysis. Participants were screened based on the following exclusion criteria :(1) persons under 18 years of age $(n=10,151) ;(2)$ Subjects with no telomere data $(n=3026) ;(3)$ Subjects without insulin data $(n=3200)$; (4) Some other data loss $(n=2200)$.(Figure 1.) This study was not a clinical trial, so no clinical registration was required. The study procedure is in line with the World Medical Association's Helsinki Declaration (see the NHANES website for details).

\section{Data Collection}

All information is collected by uniformly trained investigators. These data include demographic data (gender, age, race/ethnicity, etc.), health-related behaviors (smoking and alcohol consumption), 
anthropometric measurements (e.g., height, waist circumference, weight, etc.) and biochemical tests (TC, TG, GLU, etc.).AIA- PACK method was used to determine insulin on TOSOH AIA system analyzer. The subjects' height, weight, and waist circumference were measured according to standard protocols and techniques. BMI was calculated as follows: $\mathrm{BMI}=$ weight $(\mathrm{Kg}) /$ height $(\mathrm{M} 2)$. The cut-off points of BMI were normal (18.5-24.9kg /m2), overweight (25.0-29.9kg /m2) and obese (BMI $\geq 30.0 \mathrm{~kg} / \mathrm{m} 2)$. IR was indexed by the homeostasis model assessment (HOMA) formula: [fasting insulin $(\mu \mathrm{U} / \mathrm{mL}) \times$ fasting glucose $(\mathrm{mmol} / \mathrm{L})] / 22.5 \mathrm{In}$ this study, the value was 3.7, representing the diagnostic value of IR for the entire study population, rather than the general sample.

\section{Evaluation Criterion}

\section{Telomere}

Telomere length analysis in this trial was performed at the University of California, San Francisco using polymerase chain reaction to measure telomere length relative to standard reference DNA(T/S) ratios. Each sample was tested three times over a 3-day period, on repeated 6 Wells, to identify and rule out any potential outliers (<2\% of the sample).About all the details, please visit http://cdc.gov/nchs/nhanes lab section. The coefficient of variation between batches was $6.5 \%$. The value represents the mean (standard deviation) of the T/S ratio. The Centers for Disease Control (CDC) approved human subjects for this measure through the $\mathrm{CDC}$ Institutional Review Board and ensured quality control of the TL measurements prior to establishing a data link to the NHANES database.

\section{Smoking}

In this study, we divided smoking into two levels. Smoker: refers to having smoked more than 100 cigarettes in a lifetime or having smoked more than one cigarette on average in the last 30 days. Nonsmokers: refer to those who have smoked no more than 100 cigarettes in their lifetime or no more than one cigarette on average in the past 30 days.

\section{hypertension}

Hypertension was defined as resting systolic and/or diastolic blood pressure $\geq 140 / 90 \mathrm{mmHg}(20)$. Another relatively strict standard is based on the 2017 American College of Cardiology/American Heart Association Blood Pressure Guidelines (21).Blood pressure $<130 / 80 \mathrm{mmHg}$ is recommended as normal. Hypertension was defined as having three mean BP of $>130 / 80$ or taking hypertensive medication.

\section{Education}

In this study, we divided the educational level of the participants into two levels, one was the participants who had received higher education, or at least tertiary education. Second, those who have not received higher education, those who have not received college education or above.

\section{Income}


In this study, we divided the family income into two levels, one is the family income of less than $\$ 100,000$ a year low-income families. Second, high-income families with a household income of $\$ 100,000$ or more a year.

\section{Covariable Selection}

The potential confounders of possible associations between Telomere length and risk of insulin resistance outcomes were defined a priori based on the literature.

Our covariates were selected apriori based on our prior work and studies from others examining risk factors for insulin resistance.

\section{Statistical Approach}

In order to make the sample more representative, we use NHANES database with complex, multi-stage probability sampling design. The study looked at a nationally representative sample; Each year, 5,000 people are selected from a sampling framework of 15 different locations across all counties in the United States. The prevalence of IR is a weighted percentage of IR in the complex sample, equal to the number of IR patients divided by the total number of IR patients. The statistical analysis was performed using the $\mathrm{R}$ 3.4.3 version. Continuous variables are expressed as detailed sample descriptions, with averages and $95 \%$ confidence intervals. Classification variables are expressed as counts and weighted percentages, using complex sample frequencies. Continuous variables were compared between groups using student $t$ test or Mann-Whitney $\mathrm{U}$ test based on distribution normality, and classification variables were compared using Fisher's exact test.

We established three logistic regression models to test the risk of telomere length and insulin resistance, and analyzed the models according to covariates such as age, gender, race and BMI. After adjustment, multiple logistic regression was used to test the relationship between the risk of insulin resistance and telomere length in each subgroup.

\section{Results}

We selected the 1999-2002NHANES database to participate in this study. After screening for a variety of conditions, we selected 21,004 participants (1999-2000:9,965 cases;2001-2002:11,039 cases) and 2,427 participants were selected for the final data analysis. Participants were screened based on the following exclusion criteria :(1) persons under 18 years of age $(n=10,151)$;(2) Subjects with no telomere data $(n=3026) ;(3)$ Subjects without insulin data $(n=3200) ;(4)$ Some other data loss $(n=2200)$.(Figure 1.) This study was not a clinical trial, so no clinical registration was required. The study procedure is in line with the World Medical Association's Helsinki Declaration (see the NHANES website for details).

Of the 2,427 eligible subjects, we divided them into two groups based on whether they developed insulin resistance. 608 subjects with IR values greater than 3.7 were assigned to the insulin-exposed group and the remaining 1818 subjects were assigned to the unexposed group. The ages of the exposed group and the 
unexposed group were $50.91 \pm 17.26$ and $47.18 \pm 18.51$, respectively. The difference in age distribution between the two groups was statistically significant $(P<0.001)$, and the age of the unexposed group was significantly lower than that of the exposed group. Exposed group of body mass index (32.94 \pm 6.73$)$ higher than the unexposed group of body mass index $(26.56 \pm 4.85)$, with statistical significance $(P<0.001)$, the crowd of insulin resistance waist circumference (108.42 \pm 14.22$)$ significantly higher than that of insulin resistance in obesity $(92.61 \pm 12.79)(P<0.001)$, at the same time the occurrence of insulin resistance in patients with high blood pressure $(P=0.016)$, diabetes $(P<0.001)$ in patients with statistical significance. There were significant differences in insulin resistance among ethnic groups $(P<0.001)$, and there was no statistical significance in people who smoked or smoked with insulin $(P=0.99)$.(Table 1)

Table 2 shows the unadjusted occurred under the condition of insulin resistance and age, BMI, waist circumference, gender, age group, the relationship between the degree of education, we can conclude in this crowd, smoking or not has nothing to do with whether insulin resistance, with the increase of age, incidence of insulin resistance in the reach after age 60, each a year old, can make the incidence of the insulin increased by $90 \%(1.52,2.38, \mathrm{P}<0.0001)$, compared to women and men, the probability of occurrence of insulin resistance was reduced by $18 \%(0.69,0.99, \mathrm{P}=0.039)$.Participants without diabetes had an $87 \%$ lower risk than those with diabetes $(0.09,0.19, \mathrm{P}<0.0001)$. With the participants of high blood pressure than participants without hypertension risk increased by $35 \%(1.06,1.71, P=0.0158)$, both in terms of income also have statistical significance, in the income is greater than or equal to $\$ 100000$ in the crowd, the risk of insulin resistance than income less than $\$ 100000$ to reduce $27 \%(0.59,0.91, P<0.0001)$, and telomere length 0.01 , each additional $62 \%$ lower risk of insulin resistance $(0.26,0.56, \mathrm{P}<0.001)$. $8 \mathrm{Table}$ $2 \rrbracket$

We performed multiple logistic regression model test (table 3) on telomere length and the occurrence of insulin resistance, and found that there was no correlation between telomere length and insulin resistance after adjustment. It was concluded that there was no correlation between the risk of insulin resistance and telomere length. We created three models, model 1 without any adjustment, model 2 with adjustment of sex; age; race; education: diabetes; income, waistline; Smoking and other factors, model 3 adjusted age; sex; race; education; income; HBP; BMl; waistline; diabetes; HDL-C; TG; Smoking. We found that, in the case of without any adjustment, telomere length and insulin resistance related to $(\mathrm{OR}: 0.38(0.26,0.56) \mathrm{P}<$ 0.0001 ), the inverse ratio relation (figure 2 ), after adjusting the covariate of model 1 , found that telomere length associated with insulin resistance does not $(\mathrm{OR}: 0.64(0.39,1.05) \mathrm{P}=0.08)$, and continue to complete the adjustment model 2 , found that insulin resistance related to telomere length does not (OR: $0.64,(0.38,1.08) \mathrm{P}=0.093)$.In order to test the reliability of the results, we divided the telomere length into three groups according to the same length. Without adjustment, only the group with the longest telomere was related to the occurrence of insulin resistance (OR: 0.31(0.12,0.84 P=0.021). After the adjustment of model 2 (OR: 0.68(0.22,2.08) $\mathrm{P}=0.499)$ and model $3(\mathrm{OR}: 0.54(0.16,1.79) \mathrm{P}=0.315)$, the telomere length was also not related to the occurrence of insulin resistance.

In order to further verify the reliability of the results, we divided the population into the following pressure groups (Figure 3) for analysis. We divided the age into three groups, and the covariable adjustment was 
the same as Model 3. It was found that telomere length was not associated with insulin resistance in any population, and $P$ values were all greater than 0.05 , which was not statistically significant. We grouped by gender, and $P$ values were all greater than 0.05 . We tried to group people according to income, education, $B M I$, waist circumference, HDL, TG, etc., and found that the $P$ values were all greater than 0.05 , which was not statistically significant.

So, all of that. Based on this study, we believe that there is no correlation between telomere length reduction and insulin resistance in the adult population of the United States.

\section{Discussion}

Previous studies have shown that telomeres are nuclear protein structures that exist at the end of each chromosome arm, and their physiological function is to maintain the stability of the genome, so that normal genes are not degraded and the integrity of the genome is maintained. There are highly conserved hexamers (TTAGGG) in tandem to form highly repetitive DNA sequences, and the structure is called the ring structure of $T$ ring.$(22)$

Telomere length has previously been linked to various chronic diseases. Our primary objective was to investigate whether telomere length is associated with the risk of insulin resistance in US adults. Since telomere length is closely associated with mortality from diabetes and cardiovascular disease, this issue is very important. Insulin resistance is also considered to be an important risk factor for diabetes and cardiovascular disease. Insulin resistance has been listed as a sign of arterial aging, diabetes, and especially atherosclerosis.

In the general population, we can find that age is closely related to insulin resistance, and the risk of insulin resistance increases with the increase of age. At the same time, age is also the most important factor for telomere shortening $(23,24)$.Previous studies seem to link inflammation and oxidative stress as a unifying factor in the association of telomere shortening with atherosclerosis and insulin resistance (25). Atherosclerosis and insulin resistance are both chronic states of inert inflammation and oxidative stress (26). The presence of inflammation causes hematopoietic stem cells to proliferate in response to the inflammatory response, a phenomenon that increases telomere wear. Since the telomere $G$ triplet that makes up the TTAGGG repeats is highly sensitive to hydroxyl radicals, oxidative stress may accelerate the wear of telomere length, at least in vitro, as the loss of telomere repeats is greater with each cell replication. Therefore, adult telomere length reduction is often attributed to accelerated telomere length reduction associated with the process of insulin resistance and atherosclerosis. In our view, this concept needs a major revision, since telomere length is mainly determined before adulthood. Therefore, we can infer that if telomere length is negatively correlated with insulin resistance in adults, telomere length shortening precedes insulin resistance.

Some of the recent animal experiment, found in rodents, shorter telomeres may cause damage to the function of islet beta cells $(27,28)$, but this is unlikely to explain human telomere length and insulin resistance, because the insulin resistance to insulin is the nature of the response to insulin sensitive to the 
(29).In mice, telomere shortening appears to lead to metabolic dysfunction through mitochondrial dysfunction (30). When the telomere binding protein RAP1 was destroyed, mice showed abdominal fat accumulation, insulin resistance, and other metabolic abnormalities, suggesting that telomere biology plays a key role in body weight homeostasis $(31,32)$.

It is worth mentioning that in our current study, after adjusting multiple models, telomere length seems to have no inevitable relationship with insulin resistance. Telomeres gradually shortened with age, but there was no statistically significant difference in telomere length or insulin resistance among age groups. We divided the population into different subgroups according to different factors (Figure 3), and no statistical significance was found in telomere length and insulin resistance after adjustment.

We would like to highlight the advantages and limitations of this study. The first advantage is the population representation of this study. We used the NHANES database, which has the advantage of being nationally representative. In addition, the high precision Southern blotting method was used to measure telomere length (33).A recent study showed that quantitative PCR based methods for measuring telomere length were as reproducible as Southern blotting. However, a commentary accompanying the study questions the validity of this argument (34).Furthermore, in an objective evaluation of the two methods, the coefficient of variation between batches for quantitative PCR was found to be four times greater than that for Southern blotting (35).Secondly, our study added HDL-C and TG on the basis of previous studies, because it was found in some recent investigations that $\mathrm{HDL}$ and $\mathrm{TG}$ are the key factors affecting insulin resistance. In addition, our inclusion criteria for the population is only based on the absence of necessary data, rather than being limited to the unique samples in the usual studies, which means that our results are more representative of the general population. We wanted to show an association between telomere length and insulin resistance in the general population of the United States, rather than in a specific population. After controlling for all other confounding effects, we hoped to obtain a complementary effect representing the relationship between telomere length and insulin resistance, respectively

However, there are still some shortcomings in this study. First of all, our data are from a cross-sectional survey and the sample is uniquely representative of the sample population. The NHANES database is only representative of the general US population. Insulin resistance is ethnically specific, so our study is not applicable to other populations, and further studies are needed for other populations. Secondly, as an alternative method for the diagnosis of insulin resistance, HOMA-IR still has some limitations in its reproducibility and reliability.

\section{Conclusion}

In summary, telomere length is not associated with insulin resistance in the average American adult. Both insulin resistance and telomere length varied with age, but the deterioration between insulin resistance and telomere length was not statistically significant. This is different from some previous studies. In clinical practice, more studies are needed to analyze the relationship between telomere length and insulin resistance. Our findings, which were tested on a representative sample of American adults, provide new insights into human insulin resistance. 


\section{Abbreviations}

IR: insulin resistance Cl: confidence interval OR: odds ratio

BMI囚body mass index; HDL囚high-density lipoprotein TG: Triglyceride

\section{Declarations}

\section{Authors' contributions}

Rongpeng Gong and Xiaoxing Wei conceived the idea; Rongpeng Gong and Ya Liu wrote the manuscript; Zheng Li and Lixin Yang collected and read the literature and revised the article; Xiaoxing Wei read through and corrected the manuscript. All authors read and approved the final manuscript. Rongpeng Gong is the first author and Xiaoxing Wei is the corresponding author of this paper.

\section{Author details}

Rongpeng Gong and Xiaoxing Wei are from Medical College of Qinghai University, Xining 810016, P. R. China.

Zheng Li and Lixin Yang are from Endocrinology Department of Qinghai Provincial People's Hospital. 810016, P. R. China.

\section{Competing interests}

The authors declare that they have no competing interests.

\section{Availability of data and materials}

Not applicable.

\section{Consent for publication}

Not applicable

\section{Ethics approval and consent to participate}

All participants provided written informed consent, and the study was approved by the NCHS Research Ethics Review Board(https://wwwn.cdc.gov/nchs/nhanes/default.aspx)

\section{Funding}

This work was Supported by Grants from National Natural Science Foundation of China (81860370), General Project of Natural Science Foundation of Qinghai Province (2020-ZJ-930) and CAS "Light of West China" Program. 


\section{Acknowledgements}

Not applicable

\section{References}

1. López-Otín C., Blasco M. A., Partridge L., Serrano M., Kroemer G. The hallmarks of aging, Cell 2013: 153: 1194-1217.

2. Ford E. S., Giles W. H., Dietz W. H. Prevalence of the metabolic syndrome among US adults: findings from the third National Health and Nutrition Examination Survey, Jama 2002: 287: 356-359.

3. Morley J. E. Diabetes and aging: epidemiologic overview, Clin Geriatr Med 2008: 24: 395-405, v.

4. Adaikalakoteswari A., Balasubramanyam M., Mohan V. Telomere shortening occurs in Asian Indian Type 2 diabetic patients, Diabet Med 2005: 22: 1151-1156.

5. Ahmad S., Heraclides A., Sun Q., Elgzyri T., Rönn T., Ling C. et al. Telomere length in blood and skeletal muscle in relation to measures of glycaemia and insulinaemia, Diabet Med 2012: 29: e377-381.

6. Al-Attas O. S., Al-Daghri N. M., Alokail M. S., Alfadda A., Bamakhramah A., Sabico S. et al. Adiposity and insulin resistance correlate with telomere length in middle-aged Arabs: the influence of circulating adiponectin, Eur J Endocrinol 2010: 163: 601-607.

7. Aviv A., Valdes A., Gardner J. P., Swaminathan R., Kimura M., Spector T. D. Menopause modifies the association of leukocyte telomere length with insulin resistance and inflammation, $\mathrm{J}$ Clin Endocrinol Metab 2006: 91: 635-640.

8. Demissie S., Levy D., Benjamin E. J., Cupples L. A., Gardner J. P., Herbert A. et al. Insulin resistance, oxidative stress, hypertension, and leukocyte telomere length in men from the Framingham Heart Study, Aging Cell 2006: 5: 325-330.

9. Gardner J. P., Li S., Srinivasan S. R., Chen W., Kimura M., Lu X. et al. Rise in insulin resistance is associated with escalated telomere attrition, Circulation 2005: 111: 2171-2177.

10. Monickaraj F., Aravind S., Gokulakrishnan K., Sathishkumar C., Prabu P., Prabu D. et al. Accelerated aging as evidenced by increased telomere shortening and mitochondrial DNA depletion in patients with type 2 diabetes, Mol Cell Biochem 2012: 365: 343-350.

11. Salpea K. D., Talmud P. J., Cooper J. A., Maubaret C. G., Stephens J. W., Abelak K. et al. Association of telomere length with type 2 diabetes, oxidative stress and UCP2 gene variation, Atherosclerosis 2010: 209: 42-50.

12. Barbieri M., Paolisso G., Kimura M., Gardner J. P., Boccardi V., Papa M. et al. Higher circulating levels of IGF-1 are associated with longer leukocyte telomere length in healthy subjects, Mech Ageing Dev 2009: 130: 771-776.

13. Hovatta I., de Mello V. D., Kananen L., Lindström J., Eriksson J. G., llanne-Parikka P. et al. Leukocyte telomere length in the Finnish Diabetes Prevention Study, PLoS One 2012: 7: e34948.

14. Benetos A., Kark J. D., Susser E., Kimura M., Sinnreich R., Chen W. et al. Tracking and fixed ranking of leukocyte telomere length across the adult life course, Aging Cell 2013: 12: 615-621. 
15. Daniali L., Benetos A., Susser E., Kark J. D., Labat C., Kimura M. et al. Telomeres shorten at equivalent rates in somatic tissues of adults, Nat Commun 2013: 4: 1597.

16. Aviv A. Genetics of leukocyte telomere length and its role in atherosclerosis, Mutat Res 2012: 730: 6874.

17. Entringer S., Epel E. S., Kumsta R., Lin J., Hellhammer D. H., Blackburn E. H. et al. Stress exposure in intrauterine life is associated with shorter telomere length in young adulthood, Proc Natl Acad Sci U S A 2011: 108: E513-518.

18. Hjort L., Vryer R., Grunnet L. G., Burgner D., Olsen S. F., Saffery R. et al. Telomere length is reduced in 9to 16-year-old girls exposed to gestational diabetes in utero, Diabetologia 2018: 61: 870-880.

19. Xu J., Ye J., Wu Y., Zhang H., Luo Q., Han C. et al. Reduced fetal telomere length in gestational diabetes, PLoS One 2014: 9: e86161.

20. Mancia G., Grassi G. Joint National Committee VII and European Society of Hypertension/European Society of Cardiology guidelines for evaluating and treating hypertension: a two-way road?, Journal of the American Society of Nephrology : JASN 2005: 16 Suppl 1: S74-77.

21. Bell K. J. L., Doust J., Glasziou P. Incremental Benefits and Harms of the 2017 American College of Cardiology/American Heart Association High Blood Pressure Guideline, JAMA internal medicine 2018: 178: $755-757$.

22. Turner K. J., Vasu V., Griffin D. K. Telomere Biology and Human Phenotype, Cells 2019: 8.

23. Chen W., Kimura M., Kim S., Cao X., Srinivasan S. R., Berenson G. S. et al. Longitudinal versus crosssectional evaluations of leukocyte telomere length dynamics: age-dependent telomere shortening is the rule, The journals of gerontology Series A, Biological sciences and medical sciences 2011: 66: 312319.

24. Steenstrup T., Hjelmborg J. V., Kark J. D., Christensen K., Aviv A. The telomere lengthening conundrumartifact or biology?, Nucleic acids research 2013: 41: e131.

25. Avogaro A., de Kreutzenberg S. V., Fadini G. P. Insulin signaling and life span, Pflugers Archiv : European journal of physiology 2010: 459: 301-314.

26. Hajjar D. P., Gotto A. M., Jr. Biological relevance of inflammation and oxidative stress in the pathogenesis of arterial diseases, The American journal of pathology 2013: 182: 1474-1481.

27. Guo N., Parry E. M., Li L. S., Kembou F., Lauder N., Hussain M. A. et al. Short telomeres compromise $\beta$ cell signaling and survival, PloS one 2011: 6: e17858.

28. Tarry-Adkins J. L., Chen J. H., Smith N. S., Jones R. H., Cherif H., Ozanne S. E. Poor maternal nutrition followed by accelerated postnatal growth leads to telomere shortening and increased markers of cell senescence in rat islets, FASEB journal : official publication of the Federation of American Societies for Experimental Biology 2009: 23: 1521-1528.

29. Brown A. E., Walker M. Genetics of Insulin Resistance and the Metabolic Syndrome, Current cardiology reports 2016: 18: 75.

30. Sahin E., Colla S., Liesa M., Moslehi J., Müller F. L., Guo M. et al. Telomere dysfunction induces metabolic and mitochondrial compromise, Nature 2011: 470: 359-365. 
31. Martínez P., Gómez-López G., García F., Mercken E., Mitchell S., Flores J. M. et al. RAP1 protects from obesity through its extratelomeric role regulating gene expression, Cell reports 2013: 3: 2059-2074.

32. Yeung F., Ramírez C. M., Mateos-Gomez P. A., Pinzaru A., Ceccarini G., Kabir S. et al. Nontelomeric role for Rap1 in regulating metabolism and protecting against obesity, Cell reports 2013: 3: 1847-1856.

33. Martin-Ruiz C. M., Baird D., Roger L., Boukamp P., Krunic D., Cawthon R. et al. Reproducibility of telomere length assessment: an international collaborative study, International journal of epidemiology 2015: 44: 1673-1683.

34. Verhulst S., Susser E., Factor-Litvak P. R., Simons M. J., Benetos A., Steenstrup T. et al. Commentary: The reliability of telomere length measurements, International journal of epidemiology 2015: 44: 16831686.

35. Aviv A., Hunt S. C., Lin J., Cao X., Kimura M., Blackburn E. Impartial comparative analysis of measurement of leukocyte telomere length/DNA content by Southern blots and qPCR, Nucleic acids research 2011: 39: e134.

\section{Tables}

Table 1. Baseline characterisitics of the study participants 


\begin{tabular}{|c|c|c|c|c|}
\hline Characteristics & $\begin{array}{l}\text { All participants } \\
\mathrm{aN}=2426)\end{array}$ & $\begin{array}{l}\text { Patients with } \\
\text { Insulin } \\
\text { resistance }(\mathrm{N}=608)\end{array}$ & $\begin{array}{l}\text { Patients without } \\
\text { Insulin } \\
\text { resistance( }(\mathrm{N}=1818)\end{array}$ & $\begin{array}{l}P \\
\text { value }\end{array}$ \\
\hline \multicolumn{5}{|l|}{ Demographic } \\
\hline Age(years),mean $\pm S D$ & $48.1 \pm 18.3$ & $50.91 \pm 17.26$ & $47.18 \pm 18.51$ & $<0.001$ \\
\hline Age group & & & & $<0.001$ \\
\hline$<40$ & $916(37.76 \%)$ & $174(28.62 \%)$ & $742(40.81 \%)$ & \\
\hline $40-60$ & 764(31.49\%) & 204 (33.55\%) & $560(30.80 \%)$ & \\
\hline $60>$ & $746(30.75 \%)$ & $230(37.83 \%)$ & $516(28.38 \%)$ & \\
\hline sex & & & & 0.039 \\
\hline male,no.(\%) & $1165(48.02 \%)$ & $314(51.64 \%)$ & $851(46.81 \%)$ & \\
\hline female,no.(\%) & $1261(51.98 \%)$ & $294(48.36 \%)$ & 967 (53.19\%) & \\
\hline $\mathrm{BMI}(\mathrm{kg} / \mathrm{m} 2)$, mean $\pm \mathrm{SD}$ & $28.16 \pm 6.05$ & $32.94 \pm 6.73$ & $26.56 \pm 4.85$ & $<0.001$ \\
\hline smoker & & & & 0.99 \\
\hline never smoker,no(\%) & $1839(75.80 \%)$ & $461(75.82 \%)$ & $1378(75.80 \%)$ & \\
\hline smoker,no.(\%) & $587(24.20 \%)$ & $147(24.18 \%)$ & $440(24.20 \%)$ & \\
\hline Waist(cm),mean $\pm S D$ & $96.58 \pm 14.84$ & $108.42 \pm 14.22$ & $92.61 \pm 12.79$ & $<0.001$ \\
\hline race & & & & $<0.001$ \\
\hline Mexican American & $558(23.00 \%)$ & $182(29.93 \%)$ & $376(20.68 \%)$ & \\
\hline Other Hispanic & $104(4.29 \%)$ & $22(3.62 \%)$ & $82(4.51 \%)$ & \\
\hline Non-Hispanic White & $1291(53.22 \%)$ & $257(42.27 \%)$ & $1034(56.88 \%)$ & \\
\hline Non-Hispanic Black & $401(16.53 \%)$ & $129(21.22 \%)$ & $272(14.96 \%)$ & \\
\hline $\begin{array}{l}\text { Other Race - Including } \\
\text { Multi-Racial }\end{array}$ & $72(2.97 \%)$ & $18(2.96 \%)$ & $54(2.97 \%)$ & \\
\hline education, no.(\%) & & & & 0.002 \\
\hline $\begin{array}{l}\text { Less than college, no. } \\
(\%)\end{array}$ & $1974(81.37 \%)$ & $521(85.69 \%)$ & $1453(79.92 \%)$ & \\
\hline $\begin{array}{l}\text { College graduate or } \\
\text { above, no.(\%) }\end{array}$ & $452(18.63 \%)$ & $87(14.31 \%)$ & $365(20.08 \%)$ & \\
\hline \multicolumn{5}{|l|}{ Clinical characteristics } \\
\hline Hypertension, no.(\%) & $380(15.66 \%)$ & $114(18.75 \%)$ & $266(14.63 \%)$ & 0.016 \\
\hline $\begin{array}{l}\text { Diabetes mellitus, no. } \\
(\%)\end{array}$ & $156(6.43 \%)$ & 50 (2.75\%) & $106(17.43 \%)$ & $<0.001$ \\
\hline
\end{tabular}




\section{Serum biomarkers}

$\begin{array}{lllll}\text { Telomere length}(T / S & 1.0 \pm 0.3 & 0.98 \pm 0.23 & 1.05 \pm 0.21 & <0.001\end{array}$ ratio)

$\begin{array}{lllll}\mathrm{HDL}-\mathrm{C}(\mathrm{mmol} / \mathrm{L}) & 1.34 \pm 0.40 & 1.16 \pm 0.30 & 1.40 \pm 0.41 & <0.001 \\ \mathrm{TG}(\mathrm{mmol} / \mathrm{L}) & 1.54 \pm 0.79 & 1.92 \pm 0.85 & 1.41 \pm 0.73 & <0.001\end{array}$

Abbreviations $\triangle \mathrm{BM} \mathbb{\mathrm { B }}$ body mass index; TG,Triglyceride;HDL,high-density lipoprotein

Table 2. Univariate analysis for Insulin resistance 


\begin{tabular}{|c|c|c|c|}
\hline Covariate & Statistics & $\mathrm{OR}(95 \% \mathrm{Cl})$ & $P$-value \\
\hline Age(years),mean $\pm S D$ & $48.12 \pm 18.27$ & $1.01(1.01,1.02)$ & $<0.0001$ \\
\hline \multicolumn{4}{|l|}{ Age(years) group,mean $\pm S D$} \\
\hline$<40$ & $916(37.76 \%)$ & 1 & \\
\hline$>=40,<60$ & $764(31.49 \%)$ & $1.55(1.23,1.96)$ & 0.0002 \\
\hline$>=60$ & $746(30.75 \%)$ & $1.90(1.52,2.38)$ & $<0.0001$ \\
\hline $\mathrm{BMI}(\mathrm{kg} / \mathrm{m} 2)$, mean $\pm \mathrm{SD}$ & $28.16 \pm 6.05$ & $1.21(1.19,1.24)$ & $<0.0001$ \\
\hline Waist(cm),mean $\pm S D$ & $96.58 \pm 14.84$ & $1.09(1.08,1.10)$ & $<0.0001$ \\
\hline \multicolumn{4}{|l|}{ sex } \\
\hline male & $1165(48.02 \%)$ & 1 & \\
\hline Female & $1261(51.98 \%)$ & $0.82(0.69,0.99)$ & 0.039 \\
\hline \multicolumn{4}{|l|}{ education } \\
\hline Less than college, no.(\%) & $1974(81.37 \%)$ & 1 & \\
\hline College graduate or above, no.(\%) & $452(18.63 \%)$ & $0.66(0.52,0.86)$ & 0.0017 \\
\hline \multicolumn{4}{|l|}{ smoker } \\
\hline never smoker,no.(\%) & $1839(75.80 \%)$ & 1 & \\
\hline smoker,no.(\%) & $587(24.20 \%)$ & $1.00(0.81,1.24)$ & 0.9901 \\
\hline \multicolumn{4}{|l|}{ Diabetes mellitus, no.(\%) } \\
\hline YES,no.(\%) & $156(6.43 \%)$ & 1 & \\
\hline NO,no.(\%) & $2270(93.57 \%)$ & $0.13(0.09,0.19)$ & $<0.0001$ \\
\hline \multicolumn{4}{|l|}{ Hypertension, no.(\%) } \\
\hline NO,no.(\%) & $2046(84.34 \%)$ & 1 & \\
\hline YES,no.(\%) & $380(15.66 \%)$ & $1.35(1.06,1.71)$ & 0.0158 \\
\hline \multicolumn{4}{|l|}{ income } \\
\hline less than 10 & $1741(71.76 \%)$ & 1 & \\
\hline more than 10 & $685(28.24 \%)$ & $0.73(0.59,0.91)$ & 0.0041 \\
\hline Telomere length( $\mathrm{T} / \mathrm{S}$ ratio) & $1.03 \pm 0.26$ & $0.38(0.26,0.56)$ & $<0.0001$ \\
\hline
\end{tabular}

Table 3.The association between TL and insulin resistance in a multiple regression model 


\begin{tabular}{|c|c|c|c|c|c|c|}
\hline \multirow[t]{2}{*}{ Outcome } & \multicolumn{2}{|l|}{ Non-adjusted Model 1} & \multicolumn{2}{|l|}{ Model 2} & \multicolumn{2}{|l|}{ Model 3} \\
\hline & $\mathrm{OR}(95 \% \mathrm{Cl})$ & $P$-value & $\mathrm{OR}(95 \% \mathrm{Cl})$ & $\begin{array}{l}P \\
\text { value }\end{array}$ & OR(95\%Cl) & $\begin{array}{l}P \\
\text { value }\end{array}$ \\
\hline TL & $0.38(0.26,0.56)$ & $<0.0001$ & $\begin{array}{l}0.64 \\
(0.39,1.05)\end{array}$ & 0.08 & $\begin{array}{l}0.64 \\
(0.38,1.08)\end{array}$ & 0.093 \\
\hline \multicolumn{7}{|l|}{ TL group } \\
\hline TL1 & $\begin{array}{l}1.0015 \\
(0.1941,5.1683)\end{array}$ & 0.999 & $\begin{array}{l}1.07 \\
(0.13,8.55)\end{array}$ & 0.95 & $\begin{array}{l}1.33 \\
(0.16,11.14)\end{array}$ & 0.794 \\
\hline TL2 & $0.23(0.01,3.53)$ & 0.29 & $\begin{array}{l}0.97 \\
(0.03,28.4)\end{array}$ & 0.984 & $\begin{array}{l}0.68 \\
(0.02,23.27)\end{array}$ & 0.83 \\
\hline TL3 & $0.31(0.12,0.84)$ & 0.021 & $\begin{array}{l}0.68 \\
(0.22,2.08)\end{array}$ & 0.499 & $\begin{array}{l}0.54 \\
(0.16,1.79)\end{array}$ & 0.315 \\
\hline $\begin{array}{l}\text { Non-adju } \\
\text { educatiol } \\
\text { HBP; BM }\end{array}$ & $\begin{array}{l}\text { model adjust for: No } \\
\text { abetes;income,waisit; } \\
\text { asit; diabetes; HDL-C; }\end{array}$ & $\begin{array}{l}\text { Adjust In } \\
\text { king. Adj } \\
\text { smoking }\end{array}$ & $\begin{array}{l}\text { del adjust } f \\
\text { t II model a }\end{array}$ & $\begin{array}{l}\text {;age; } \\
\text { or: ag }\end{array}$ & x; race; edu & incom; \\
\hline
\end{tabular}

\section{Figures}




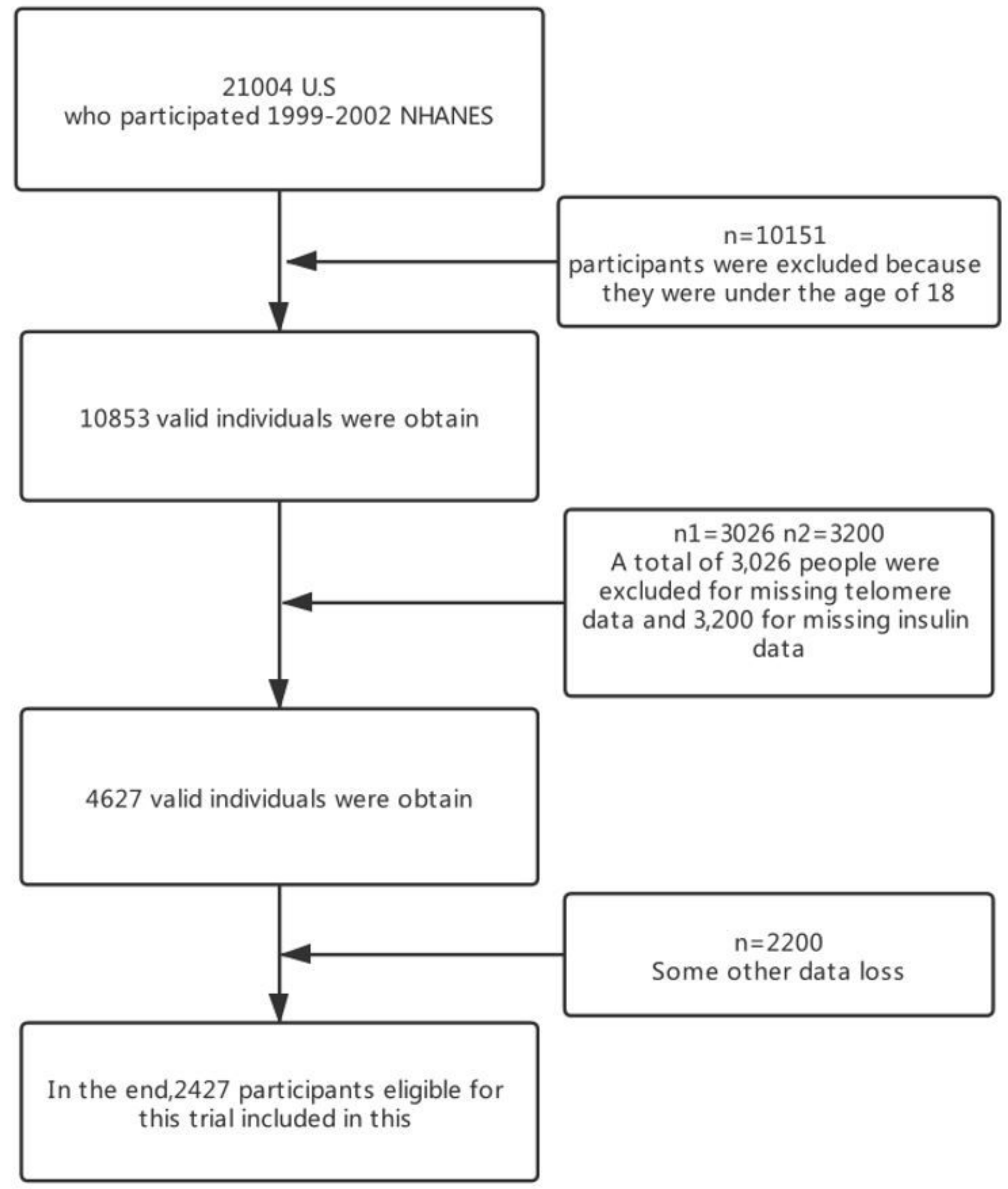

Figure 1

Flowchart of patient selection. 


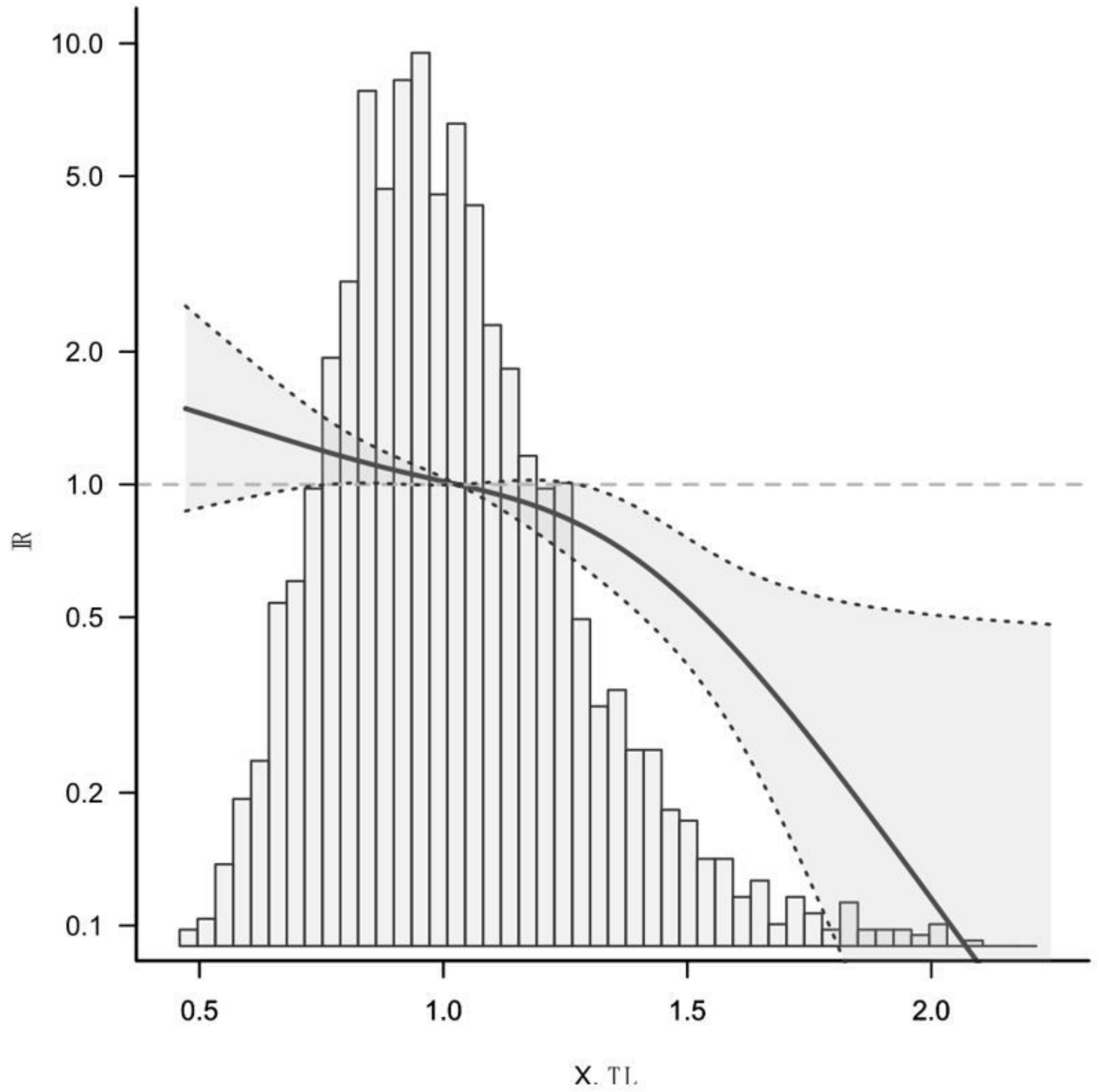

Figure 2

Association between TL and IR.(Not adjust) Notes: The two blue lines represent estimates and their corresponding $95 \%$ confidence intervals. 


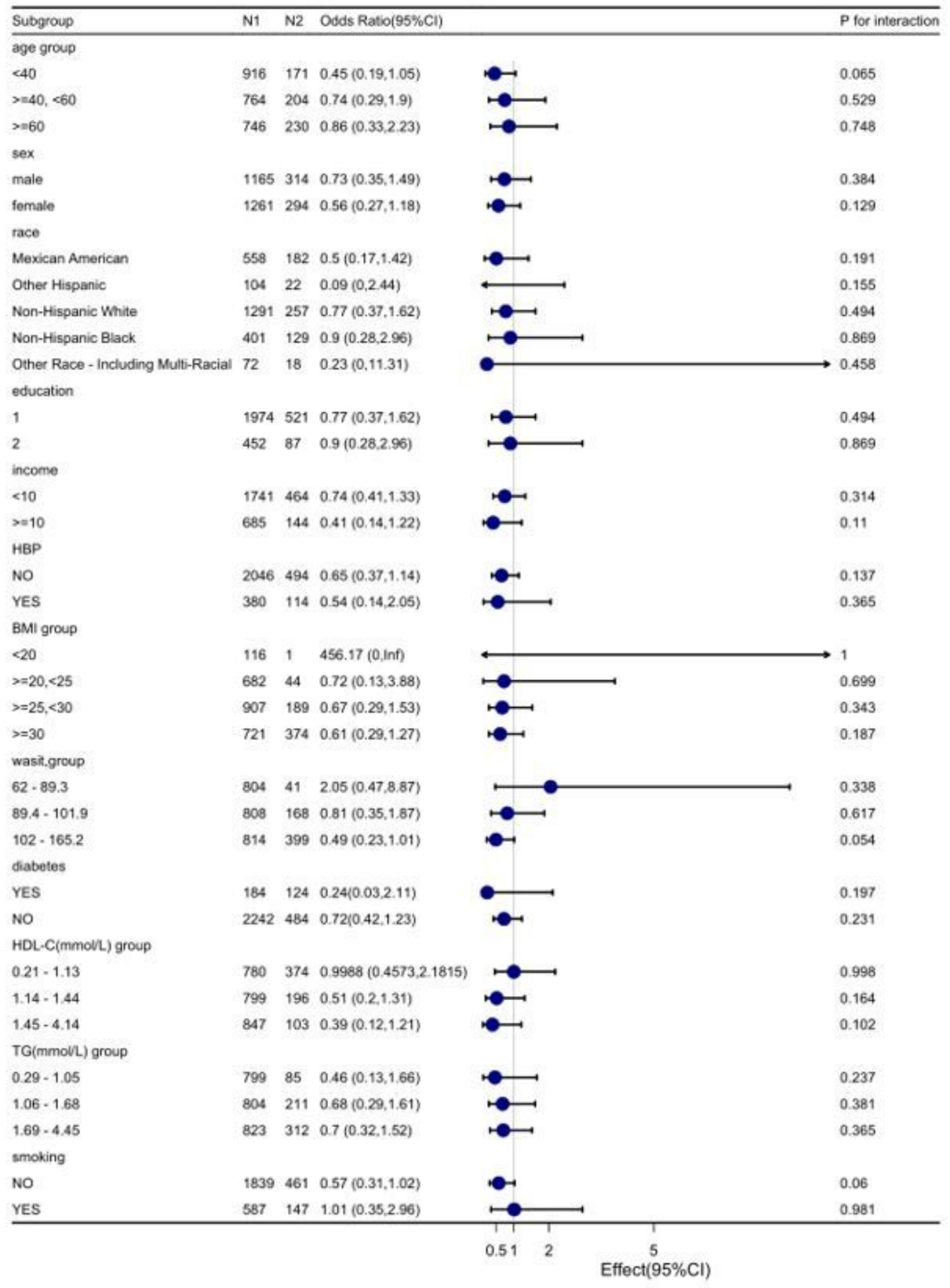

\section{Figure 3}

Association of TL with risk of incident. Notes: All groupings are adjusted according to Model 3 